$\underline{\text { Leading Article }}$

\title{
Periodic deworming practice in Sri Lanka: Is it based on evidence, misconceptions or commercialism?
}

\author{
Sachith Mettananda ${ }^{1}$, Harendra de Silva ${ }^{2}$ \\ DOI: http://dx.doi.org/10.4038/sljch.v46i4.8375 \\ Sri Lanka Journal of Child Health, 2017; 46(4): 307-311 \\ (Key words: worm infections, geo-helminth, pinworm, public health interventions, deworming)
}

\section{Introduction}

Geo-helminth ("worm") infections are a universal health problem which predominantly affects the impoverished and underdeveloped communities in the developing world. Geo-helminths commonly infect the gastrointestinal tract of humans and result in significant morbidity particularly among preschool and school children ${ }^{1}$. Here we review the changing epidemiology of intestinal geo-helminth infections and critically evaluate the perception and practice of periodic deworming, the economic impact and the present public health interventions in controlling the disease burden in Sri Lanka.

\section{Geo-helminth versus pinworm (Enterobius vermicularis) infections}

Geo-helminths infect both small and large intestine and have life cycles that include moulting in the soil (hence the term "Geo"). The main species which cause human disease in Sri Lanka are; roundworm (Ascaris lumbricoides), whipworm (Trichuris trichiura) and hookworm (Necator americanus \& Ancylostoma duodenale). In contrast, pinworm (Enterobius vermicularis), though being an intestinal helminth, is not a geo-helminth since it does not have a cycle or moult in the soil.

Infections due to roundworm and whipworm are transmitted by ingestion of helminth fertilised eggs that have moulted in the soil. Ingested eggs hatch in the intestine to release larvae that undergo several moults either in the lungs (roundworm) or intestine (whipworm) to develop into adult worms.

\footnotetext{
${ }^{1}$ Senior Lecturer, Department of Paediatrics, Faculty of Medicine, University of Kelaniya, Sri Lanka and Consultant Paediatrician, Colombo North Teaching Hospital, Ragama, Sri Lanka

${ }^{2}$ Professor (Emeritus), Department of Paediatrics, Faculty of Medicine, University of Colombo, Sri Lanka

*Correspondence: harendra51@gmail.com
}

The authors declare that there are no conflicts of interest

Open Access Article published under the Creative

Commons Attribution CC-BY License
Hookworm eggs moult and hatch in the warm moist soil and the infective larvae infect humans by penetrating through the skin to enter the intestine via the lungs. In contrast, pinworms live primarily in the human caecum from which the gravid females migrate at night to lay thousands of eggs on the anal area. Self-infection and infection of others occur by ingestion of eggs that are carried on fingernails, clothing or bedding.

Epidemiology and risk factors associated with geohelminth and pinworm infections are different, too. Geo-helminths are found predominantly in the tropical and subtropical areas of the world wherever adequate moisture and warm temperatures prevail ${ }^{2}$. Well established risk factors for increased transmission of geo-helminths include poverty, inadequate water supplies, poor sanitation, faecal contamination of soil, use of human faeces as fertilizer and geophagia. In contrast, pinworm is found worldwide including developed countries, and in fact, is the commonest intestinal parasite in the United States despite high sanitary standards and lack of faecal contamination of soil. It infects individuals of all ages and socio-economic levels ${ }^{3}$.

Further, medical complications related to geohelminths are distinct from the health issues caused by pinworms. Main health issues due to geohelminths in children are malnutrition, growth stunting, intellectual retardation, cognitive and educational deficits and anaemia (hook worm only) ${ }^{4}$. In contrast, health problems due to pinworms are relatively mild and are limited to the perineal and perianal irritation caused by the egg deposition and vaginal irritation due to the rare migration of adult worms into the female genital tract. Constant itching to relieve irritation can lead to sleep disturbances.

\section{Epidemiological changes of helminth infections} in Sri Lanka

Owing to the geographical location in the tropics and the warm humid climate, geo-helminthiasis has been a long-standing health problem in Sri Lanka. Early studies examining the prevalence of geohelminths in Sri Lanka have reported extremely high figures. A study done in an urban slum community in Colombo in $1981^{5}$ reported the infection rate as 
$100 \%, 68 \%$ having dual infections and $15 \%$ being infected with all three species. Prevalence of different species were: roundworm-91\%, whipworm- $91 \%$ and hookworm- $16 \%$ and it was interesting to note the relatively low prevalence of hookworm even 30 years ago. Comparable results were reported in studies done in poor communities in Galle (prevalence - 95\%) ) $^{6}$ and plantation sector (prevalence $-90 \%)^{7}$ in the early 1990s. All three papers $^{5-7}$ report very poor living conditions in these communities with limited access to water, a small number of non-water sealed community latrines and improper sewage drainage.

However, the current prevalence of geo-helminths in Sri Lanka has plunged to an extremely low level ${ }^{8}$. A national survey done about 15 years ago (20022003 ) reported that only $6.9 \%$ of children has geohelminths with very low prevalence of all three species (roundworm-2.8\%, whipworm-4.0\% and hookworm-1.2\%) ${ }^{9}$. These low figures were confirmed by subsequent studies which identified regional variations with low- and high- prevalence areas $^{10-12}$. A study done in 2012 reported an extremely low prevalence $(1.8 \%)$ of all geohelminths ${ }^{10}$ in the Gampaha district (a semi-urban district of Sri Lanka) and similar low rates (roundworm-2\%, whipworm- $0.7 \%$ and hookworm$5 \%$ ) were reported in rural areas of Sri Lanka ${ }^{11}$. In contrast, a study done in 2009 in the plantation sector spreading across Nuwara-Eliya, Badulla, Kegalle, Ratnapura and Kandy districts reported the prevalence of geo-helminths as $29 \%$ (roundworm$24 \%$, whipworm- $6 \%$ and hookworm-5\%). This is most likely due to poor housing, sanitation and literacy in the plantation sector in Sri Lanka ${ }^{13}$.

Several factors, more importantly, improvement in socio-economic status, sanitation and personal hygiene as well as periodic treatment by individuals (although there were no organized mass treatment programmes) have contributed to the decline in the prevalence of geo-helminths in Sri Lanka. Sri Lanka has graduated from the low-income country list of the World Bank to become a low-middle income country with a per capita income of US\$ $3,780^{14}$. With the implementation of several developmental projects, the proportion of the Sri Lankan population who have permanent shelter and sanitary latrines has increased. Notably the 'Million Houses Programme' adopted under the United Nations year of housing ${ }^{15}$ ensured the construction of at least one latrine in every house. Additionally, migration of workers to the Middle-East has improved the economy of the poorest of the poor that enabled them to afford a latrine including in urban slums. These interventions have contributed to the extremely high coverage (over 90\%) for safe drinking water and sanitation in Sri Lanka ${ }^{16}$. Another programme that would have had an impact on the prevalence of geo-helminths may have been the scientifically carried out meticulous filariasis eradication programme that used anti-helminthics on a mass scale in selected areas ${ }^{17}$.

There have been only a few studies which assessed the burden of pinworm infection in Sri Lanka. This is probably due to the cumbersome test to identify pinworm and to the trivial nature of health problems caused by the pinworm. A study done in 2014 in the Colombo Municipal Council area of Sri Lanka, revealed that $42 \%$ of children aged between 3 to 7 years had pinworm infections ${ }^{18}$. Another study done in the Ragama Medical Officer of Health area reported a prevalence of $38 \%{ }^{19}$. These results are consistent with our personal experience and the prevalence of pinworm infections has been unchanged over the years and remains high. This is not surprising as pinworm is still the main intestinal parasite even in developed countries in the world ${ }^{1}$.

As stated before, a common misconception that prevails among health care professionals and the general population is the confusion between geohelminths due to faecal contamination of soil and pinworm infection (which has a high prevalence) which has a different mode of transmission. This is confounded by the terminology which uses 'worm' (Sinhala 'panuwa' or Tamil 'poochi') to refer to both pinworm and geo-helminths. We believe that it is important to eliminate this misconception as strategies for prevention and treatment are distinct for geo-helminths and pinworms.

\section{Current public health control strategies against geo-helminths}

The WHO currently recommends periodic administration of anthelmintic medications to preschool and school-age children in high and moderate risk populations as a strategy to control geo-helminths (preventive chemotherapy) ${ }^{19}$. In high-risk communities where the prevalence of geohelminth infections is over $50 \%$, it recommends mass treatment with a single dose of albendazole $400 \mathrm{mg}$ or mebendazole $500 \mathrm{mg}$ at least twice a year. In moderate-risk communities where prevalence is $20-50 \%$, once-yearly treatment is recommended ${ }^{8,20}$. For those communities classified as low-risk (prevalence below 20\%) selective treatment of individuals diagnosed with infections is endorsed (selective chemotherapy). In addition, health education to prevent re-infection and breaking the infective cycle by improvement of supply of water, sanitation and personal hygiene to reduce soil contamination with infective eggs is critical.

Based on WHO recommendations, several rounds of deworming with either mebendazole or albendazole has been used in Sri Lanka since 1994 without monitoring of the response in prevalence rates ${ }^{8}$. 
Current guideline of the Ministry of Health on deworming of children recommends regular antihelminthic treatment to pre-school children between eighteen-months to five-years and school children ${ }^{21}$. In high-risk areas (Uva, Sabaragamuwa and Central provinces) it recommends a single dose of mebendazole $500 \mathrm{mg}$ twice a year and in moderate risk areas (all other provinces), mebendazole is given once a year.

These recommendations of periodic de-worming have raised several concerns. Firstly, the recommendations are based on the assumptions of prevalence of geo-helminths to be $20-50 \%$ in 'highrisk' areas and $10-20 \%$ in 'moderate risk' areas rather than on evidence-based prevalence data. Secondly, it is likely that the interpretation of high prevalence may be in fact the prevalence of pinworm rather than geo-helminths. Thirdly, the health authorities may have adopted routine periodic de-worming with an aim to reduce the burden of anaemia due to hookworm. This is again erroneous as we have previously shown that anaemia in Sri Lankan children is not necessarily due to iron deficiency. At the same time routine deworming will not be helpful since the prevalence of hookworm infection is extremely low ${ }^{22}$.

Therefore, it is crucial not to extrapolate WHO recommendations (which were developed for extremely poor countries) without relevant evidence based data, as it could be harmful for the people and the economy of the country. For example, the calculation based on the current deworming guideline of Sri Lanka (General Circular Letter No. 02-172/2012 of the Ministry of Health) has shown that the programme will require 6.2 million tablets of mebendazole $(500 \mathrm{mg})$ annually. Based on the current purchase price of the Medical Supplies Division of the Ministry of Health (Rs. 8.15 per tablet, personal communication) this will incur an annual cost of over Rs. 50 million to the health budget $^{21}$. Based on the current price of the State Pharmaceuticals Corporation (Rs. 4.20 per tablet ${ }^{23}$ ) this will incur an annual cost of over Rs. 25 million to the health budget ${ }^{21}$. This will be only the direct cost of medication and does not take account of other indirect expenditure associated with the delivery of the programme. Moreover, the Family Health Workers who are responsible for the deworming programme are likely to emphasise on regular treatment rather than on the prevention of faecal contamination of soil or the education of public on the mode of infection and prevention of pinworm infections (Personal observation of H.de S). A current strategy to evaluate the treatment response or the change in knowledge and practices is not evident.
Furthermore, prevention and control of pinworm infection cannot be achieved by the measures suggested to control geo-helminths in the current action programme. The single-dose anti-helminthic treatment is not effective and two doses of mebendazole $100 \mathrm{mg}$ should be given 1-2 weeks apart to effectively treat pinworm infections. A repeat dose is essential to eliminate new parasites hatched from eggs as mebendazole is not effective against parasite eggs. More importantly, all household contacts (including adults) of the symptomatic index case should be treated simultaneously. Health education on improving personal hygiene with cleaning of bed linen should be provided to prevent re-infections ${ }^{1}$.

Commercialization of anti-helminthic treatment It is an un-documented fact that many general practitioners and specialists prescribe 3, 4, or 6monthly worm treatment routinely to their patients. Is this a necessity or a strategy adopted to get the patients down for another visit? These treatment regimens are usually 3 -day regimes of mebendazole (100mg twice a day) or single high-dose (500mg) regimes irrespective of the symptoms and often for unrelated symptoms or even without symptoms. It is critical for the practitioner to distinguish the problem, educate the parents, and give treatment appropriately. If pinworm is treated inappropriately without a repeat dose 1-2 weeks later and treatment of the family, invariably the child would get reinfected within a month or two necessitating an early re-visit. Hence inappropriate regular deworming becomes a mal-practice with or without the knowledge of the practitioner and becomes more of a "culture" with parents demanding treatment because of the re-emergence of perianal itching. Another issue is; the medical practitioner may attribute symptoms of anorexia, abdominal pain, teeth grinding, and other non-specific symptoms to worm infections when they are unable to find a specific diagnosis, which in turn compels parents to seek 'worm' treatment for such nonspecific symptoms.

\section{An evidence-based strategy for Sri Lanka}

With recent studies reporting low prevalence (less than $10 \%$ ) of geo-helminths, it is timely that we revisit the control and preventive strategies to combat burden of all types of worm infections including geo-helminths and pinworms. It is evident that we do not need mass drug administration of the general child population or twice or once-yearly routine deworming as recommended by the WHO in other poorer countries. Therefore, we suggest;

1. Routine administration of anthelminthic drugs should be limited to the areas with a high prevalence (e.g. Nuwara-Eliya, Badulla, Kegalle, Ratnapura and Kandy districts), that too in specific selected 
populations with high prevalence such as in estate communities.

2. In other areas, selective treatment of individuals diagnosed with infections as indicated in stool examination or passage of worms (one should be able to distinguish pinworm from geo-helminths) should be recommended. Regular deworming in the low prevalence areas should be discouraged.

3. Strategies to reduce faecal contamination of the soil should be adopted. This should include training of trainers especially the Family Health Workers, health education on the mode of infection and provision of latrines especially for estate communities.

A different approach could be implemented to control pinworm infections:

1. Children with symptomatic pinworm infections and their close contacts should be appropriately treated simultaneously with mebendazole $100 \mathrm{mg}$ followed by a repeat dose 1-2 weeks later.

2. Most importantly the difference in mode of transmission, life cycle, disease related complications, prevention and effective treatment of pinworm and geo-helminth infections should be emphasised to all health care professionals and subsequently to mothers and the general population. Schools can be used for such training.

\section{References}

1. Kucik CJ, Martin GL, Sortor BV. Common intestinal parasites. American Family Physician 2004; 69(5):1161-8.

PMid: 15023017

2. de Silva NR, Brooker S, Hotez PJ, Montresor A, Engels D, Savioli L. Soiltransmitted helminth infections: updating the global picture. Trends in Parasitology 2003;19(12):547-51.

https://doi.org/10.1016/j.pt.2003.10.002

PMid: 14642761

3. CDC. Parasites - Enterobiasis (also known as Pinworm Infection) 2013 [updated January 10, 2013. Available from: https://www.cdc.gov/parasites/pinworm/e pi.html. (Access date: 30.07.2017)

4. Bethony J, Brooker S, Albonico M, Geiger SM, Loukas A, Diemert D, et al. Soiltransmitted helminth infections: ascariasis, trichuriasis, and hookworm. Lancet 2006; 367(9521): 1521-32.
https://doi.org/10.1016/S0140-

6736(06)68653-4

5. De Silva DGH, Jayatilleka SM. The prevalence and severity of soil transmitted helminths in an urban slum community in Colombo. Ceylon Medical Journal 1981; 26(4):160-4.

PMid:7348610

6. Hettiarachchi SP, De Silva DGH, Fonseka PH. Geohelminth infection in an urban slum community in Galle. Ceylon Medical Journal 1989; 34(1):38-9.

PMid: 2788036

7. Sorensen E, Ismail M, Amarasinghe DK, Hettiarachchi I, Dassenaieke TS. The prevalence and control of soil-transmitted nematode infections among children and women in the plantations in Sri Lanka. Ceylon Medical Journal 1996; 41(2):3741.

PMid: 8771940

8. de Silva N, Jayawickrama H. Can we eliminate soil-transmitted helminth infections in Sri Lanka? Ceylon Medical Journal 2012; 57(1):1-4.

https://doi.org/10.4038/cmj.v57i1.4191

PMid: 22453703

9. Pathmeswaran A, Jayatissa R, Samarasinghe S, Fernando A, de Silva RP, Thattil RO, et al. Health status of primary schoolchildren in Sri Lanka. Ceylon Medical Journal 2005; 50(2):46-50.

PMid: 16114767

10. Gunawardena S, Gunawardena NK, Kahathuduwa G, Karunaweera ND, de Silva NR, Ranasinghe UB, et al. Integrated school-based surveillance for soiltransmitted helminth infections and lymphatic filariasis in Gampaha district, Sri Lanka. American Journal of Tropical Medicine and Hygiene 2014; 90(4):661-6. https://doi.org/10.4269/ajtmh.13-0641 PMid: 24493672 PMCid: PMC3973510

11. Fernando SD, Paranavitane SR, Rajakaruna J, Weerasinghe S, Silva D, Wickremasinghe AR. The health and nutritional status of school children in two rural communities in Sri Lanka. Tropical Medicine and International Health 2000; 5(6):450-2. https://doi.org/10.1046/j.1365-

3156.2000.00569.x

PMid: 10929146 
12. Gunawardena K, Kumarendran B, Ebenezer R, Gunasingha MS, Pathmeswaran A, de Silva N. Soiltransmitted helminth infections among plantation sector schoolchildren in Sri Lanka: prevalence after ten years of preventive chemotherapy. PLoS Neglected Tropical Diseases 2011; 5(9):e1341. https://doi.org/10.1371/journal.pntd.00013 41

PMid: 21980549 PMCid: PMC3181244

13. Gunatilaka R, Wan G, Chatterjee S. Poverty and Human Development in Sri Lanka. Manila: Asian Development Bank; 2009.

14. World Bank. World development indicators database 2016 (updated 08/02/2017). Available from:

http:/databank.worldbank.org/data/Views/ Reports/ReportWidgetCustom.aspx?Repor t_Name $=$ CountryProfile $\& I d=b 450 f d 57 \& t$ bar $=y \& d d=y \& i n f=n \& z m=n \&$ country $=$ LK A. (Access date: 30.07.2017)

15. RRANotes. The million houses programme in Sri Lanka. London: International Institute for Enviornment and Development; 1994.

16. WHO. UN-Water Global Analysis and Assessment of Sanitation and DrinkingWater 2015 [Available from: http://www.who.int/water sanitation healt $\mathrm{h} /$ monitoring/investments/srilanka-10nov.pdf?ua=1 (Access date: 30.07 .2017 )
17. Yahathugoda $T$, Weerasooriya $M$, Samarawickrema W. Elimination of Lymphatic Filariasis in Sri Lanka: How an independent research group supported the programme. Global Alliance to Eliminate Lymphatic Filariasis.

18. Kumarendran B, Pathmeswaran A, de Silva $\mathrm{N}$. Prevalence of pinworm infection among children living in low income settlements in Colombo Municipal Council area. Ceylon Medical Journal 2017; 62 (Supplement 1):94.

19. Gunawardena NK, Chandrasena TN, de Silva NR. Prevalence of enterobiasis among primary school children in Ragama, Sri Lanka. Ceylon Medical Journal 2013; 58(3):106-10.

20. WHO. Helminth control in school-age children: A guide for managers of control programmes. 2nd ed. Geneva: WHO; 2011.

21. MOH. Guidelines on deworming children and pregnant women in community setting: 2013-2016. In: Health Do, editor. Colombo 2012.

22. Mettananda S, de Silva DG. Anaemia in children: are we using the correct prevention strategies? Ceylon Medical Journal 2017; 62(2):73-6.

https://doi.org/10.1371/journal.pntd.00013 41

PMid: 21980549 PMCid: PMC3181244

23. State Pharmaceuticals Corporation of Sri Lanka. Price comparison. Available from: http://www.spc.lk/pub/pricecomparison.p df. (Access date: 30.07.2017) 